\title{
'A past built on difference, a future which is shared' - a critical examination of the recommendations made by the Commission on Integration and Community Cohesion
}

\author{
Derek McGhee* \\ University of Southampton
}

\begin{abstract}
In this article I critically examine the interim statement and final report of the Commission on Integration and Community Cohesion (CICC) produced in 2007. The article explores the CICC's attempts to distance their approach to building community cohesion and increasing integration from what they describe as the 'simplistic' explanations and recommendations adopted by previous high-profile reviews, especially the Cantle chaired Community Cohesion Review of 2001. However, it will be suggested here that the CICC have unwittingly reproduced many of the latter's problematic explanations and recommendations. The 'cultural' explanations, and recommendations, epitomized by the 'contact hypothesis' and Cantle's co-option of social capital theory are fully present in the CICC's statement and reports. This is most evident in their recommendations on 'single group funding'.
\end{abstract}

Keywords: community cohesion, integration, multiculturalism, shared futures, new ethnicities, single group funding, multiple identities.

\section{Introduction}

There has been a great deal written about community cohesion and integration in recent years. Much of the academic work in this area has been in response to a number of high profile reports, reviews, strategies and White Papers. ${ }^{1}$ This article focuses on the most recent review in this area of public policy undertaken by the Commission on Integration and Community Cohesion (CICC). The CICC was launched on the 24th August 2006, the interim statement entitled Our Interim Report was released in February 2007 and the final report entitled Our Shared Future was published June $2007 . .^{2}$ In the article I will describe the CICC's statement and report as including a strategy dedicated to generating discursive 
p. 49. 'A Past Built on Difference, a Future which is Shared' - a Critical Examination of the Recommendation made by the Commission on Integration and Community Cohesion

coherence (Modood, 2007:98) amongst a range of academic and political discourses on, for example, multiculturalism, residential segregation and 'British' identity/ies. At the same time I will also critically examine the CICC's attempts to create distance between its recommendations and those of previous high profile community cohesion reviews, strategies and discourses which it deems to be flawed; especially those which have overemphasized residential segregation, for example, the Cantle Report and some of the statements released by the Commission for Racial Equality (CRE), especially those made by Trevor Phillips. With regards to the latter it will be argued here that the CICC's recommendations are Cantlesque in their overwhelming emphasis on cultural differences (at the expense of structural inequalities). At the same time, it will also be suggested here that the CICC's recommendations are just as reductive as the Cantle Report and Trevor Phillips's emphasis on residential segregation in that the CICC simplify the integration and community cohesion challenge in Britain to the project of reducing the competition for scarce resources between groups in local areas. I will also explore the CICC's reliance on the discourse of 'multiple' complex 'real world' identities to promote their 'shared futures' strategy and to legitimize their recommendations on 'single group funding'. It will be argued here that the CICC's discourse of multiple identities is a one-sided and reductive misreading of Stuart Hall's original 'new ethnicities' theory of multiple, fluid and complex identities, in that the CICC fails to appreciate that multiplicity with regards to identities does not prevent individuals and groups from experiencing increasingly differentiated discriminations, inequalities and social exclusions.

The article will be divided into four parts. In part 1 the CICC's attempts to distance themselves from previous community cohesion and integration strategies and discourses will be explored. For example, as noted above, they attempt to distance themselves from what they describe as the unhelpful over-emphasis on residential segregation found in the Cantle report and in Trevor Phillip's speeches when he was head of the CRE. In this part I will also examine the CICC's attempts to avoid the one-size-fits-all, top-down national strategies for building community cohesion in the UK associated with strategies introduced after the disturbances in Oldham, Bunley and Bradford in 2001, in favour of bottom-up strategies that emphasise the local and distinctive community cohesion and integration patterns of distinctive areas.

In part 2 I will contextualize the CICC's opposition to multiculturalism within the populist critiques of multiculturalism. Here I will critically examine the CICC's focus on what they view as the source of 'tensions over diversity' in local areas, that is, perceptions of preferential treatment. It will be argued that the CICC's position on multiculturalism is less a principled opposition to multiculturalism and more a reflexive avoidance of what has become the politicized negative legacy of multiculturalism in British society. At the same time their recommendations with regards to 'visible social justice' will be presented here as an explicitly reflexive project designed to interrupt what they present as the main obstacle to building community cohesion and increasing integration in contemporary Britain: perceptions of preferential treatment.

Despite their protestations regarding on-size-fits all 'national' strategies for building community cohesion and increasing integration, the CICC employs its own 'national level' strategy (borrowed from Northern Ireland) to promote the idea of a 'shared future' in mainland Britain. In part 3, I will explore how the CICC combine their promotion of a discourse of multiple identities with the discourse of 'shared futures' to promote their 'past built on difference - a future which is shared' agenda. The discourse of multiple identities is also central to the CICC's recommendations for ending what they see as the root cause 
p. 50. 'A Past Built on Difference, a Future which is Shared' - a Critical Examination of the Recommendation made by the Commission on Integration and Community Cohesion

of antagonisms between 'communities of identity' in local areas, that is, single group funding. In part 4, I will contextualize the CICC's discourse of multiple identities in relation to their recommendation with regards to single group funding within new ethnicities literatures and the subsequent critiques of the latter. At the same time, it will be pointed out in parts 3 and 4 that the CICC's uncritical adoption of social science critiques of multiculturalism (as being both essentialist and divisive) has in turn resulted in them reproducing a rather essentialist understanding of 'communities of identity' associated with the much derided 'contact hypothesis' derived from Putnam's social capital theory.

\section{Part 1: Promoting a complex, local perspective}

In their final report the CICC re-asserted what they had already stated in their interim statement, that the emphasis on residential segregation amongst settled communities was 'an unhelpful focus for debates' (2007b: 119). By making repeated statements such as these the CICC were distancing themselves from the highly influential Cantle chaired Community Cohesion Review Team Report ${ }^{3}$ which introduced the discourse of "parallel lives' and a raft of recommendations which have been dismissed as advocating a simplistic 'contact hypothesis' (Kalra 2002, Kundnani 2001a; 2001b, Amin 2002, McGhee 2003; 2005, Commission on British Muslims and Islamophobia 2004). At the same time the CICC (and in particular chair Darra Singh) poked fun at Trevor Phillip's controversial speech 'After $7 / 7$ ' by modifying Phillips's sub-title 'Sleep Walking into Segregation'. For example, in the foreword of the Final report, Singh suggested that the excessive coverage by media and politicians alike on residential segregation 'serves to spread the view that the whole of England is spatially segregated. It overstates and oversimplifies the problem and leaves us "sleepwalking into simplicity"' (CICC 2007b: foreword). Rather than focus on one 'social problem' (for example, residential segregation) the CICC suggested that cohesion and integration depends upon 'a series of interacting factors' (2007b: 24). In the final report the CICC presented a new six bulletin point definition of an integrated and cohesive community. ${ }^{4}$ An integrated and cohesive community is one where:

- There is a clearly defined and widely shared sense of the contribution of different individuals and different communities to a future vision for a neighbourhood, city, region or country

- There is a strong sense of an individual's rights and responsibilities when living in a particular place - people know what everyone expects of them, and what they can expect in turn

- Those from different backgrounds have similar life opportunities, access to services and treatment

- There is a strong sense of trust in institutions locally to act fairly in arbitrating between different interests and for their role and justifications to be subject to public security

- There is a strong recognition of the contribution of both those who have newly arrived and those who already have deep attachments to a particular place, with a focus on what they have in common 
p. 51. 'A Past Built on Difference, a Future which is Shared' - a Critical Examination of the Recommendation made by the Commission on Integration and Community Cohesion

- There are strong and positive relationships between people from different backgrounds in the workplace, in schools and other institutions within neighbourhoods. (CICC 2007b: 10)

This list of the ingredients of an integrated and cohesive community has a distinctively local focus. The emphasis on particular places, neighbourhoods and communities is part of the CICC's strategy of introducing new models of integration and community cohesion. In many ways, what the CICC propose amounts to a shift away from the Home Office's 'national level' strategies in the aftermath of the social disorder in Oldham, Burnley and Bradford in 2001, which were dedicated to 'one size fits all' integration and community cohesion models. Instead the CICC is promoting a new model of integration that attempts to get to grips with British 'diversity patterns' across regions, with an emphasis on the particularity of different 'problems' and the solutions they require in different areas. The remit for establishing the new Commission ${ }^{5}$ was set out by Darra Singh in his foreword to the Interim Statement. Singh stated that a number of challenges for promoting integration and community cohesion have been with us for sometime including: tackling poverty and inequality, improving housing, employment and raising the educational potential of all (Singh, in CICC 2007a:2). However, Singh suggested that the new Commission had been set up to tackle 'new elements' associated with 'new and complex pictures of diversity in local communities, reflecting globalization and economic change' (2007a:2). For Singh, the new challenges that the Commission was established to deal with are associated with the accelerated pace of change in recent years associated with migration. Singh stated that the "patterns of immigration to the UK and temporary migration for work purposes have altered dramatically and the countries of origin and the destinations of choice are now very different' (2007a:2). This has in turn added to what Singh describes as 'the growing crisis in confidence in who we are as a society and what binds us together' (2007a:2).

Ruth Kelly (the former Secretary of State for Communities and Local Government) extended Sign's observations with regards to the remit and challenges the CICC was set up to tackle in her speech launching the CICC. According to Kelly the CICC was established partly to rise to the complexity of contemporary in-migration in Britain. For Kelly the CICC was set up to rise to the challenge of facing "the possibility that we are experiencing diversity no longer as one country but as a set of local communities each experiencing changes in a different way' (Kelly 2006a:2). As well as attempting to promote the idea that there are different types of integration and community cohesion 'problems' to be dealt with in very different types of areas across the UK the CICC also attempted to introduce a new type of British Citizenship appropriate for a much changed Britain. The CICC's perspective on how to rekindle a sense of British citizenship in this dynamic context is subtly different from the 'top-down' process of attempting to establish shared British values which was initiated by the former Home Secretary David Blunkett found in the Strength in Diversity Consultation Strategy (launched in May of 2004). In his speech launching the Strength in Diversity Consultation Strategy, the former Home Secretary said:

Integration in Britain does not mean assimilation into a common culture so that original identities are lost. Our approach is pragmatic, based on common sense, allowing people to express their identity within a common framework of rights and responsibilities. (Blunkett 2004:6). 
p. 52. 'A Past Built on Difference, a Future which is Shared' - a Critical Examination of the Recommendation made by the Commission on Integration and Community Cohesion

At the heart Blunkett's model of integration is the promotion of '...a wider concept of active citizenship' (Blunkett 2004:7). For Blunkett 'active citizenship' was an integrative concept replacing assimilationist and multiculturalist strategies (Blunkett 2002a:6). Although the CICC's model of citizenship, like the citizenship model advocated by Blunkett, is based on a set of rights and responsibilities underpinned by 'active' engagement, the $\mathrm{CICC}$ carry their emphasis on the local and the particular (as found in their model for integration and community cohesion) into their model for revitalizing British citizenship. What the CICC propose is 'a working sense of citizenship' that:

Recognizes the importance of how individuals, people and communities identify with particular places, generating both local and national responses to issues around what is expected of them, and what they can expect of others.

(CICC 2007b:62).

This is a sense of citizenship designed to 'chime at a national as well as a local level' (CICC 2007b:62) within an over-arching discourse of shared futures (see part 3). In many ways the entire approach adopted by the CICC is testament to its Chair's professional biography. Darra Singh is a local Government man through and through. ${ }^{6}$ As will be noted above and will be further explored in the next part of the article, Singh's appreciation of the challenges facing contemporary Britain and his solutions to increasing integration and improving community cohesion rarely rise above the level of 'the local' and 'the particular'. One gets the impression (as will be further developed below) that for Singh, for example, 'the nation' is an abstract concept belonging to a less complex age, his preference is for concrete and practical concepts, models and solutions. In the next part the emphasis is once again on 'the local' and 'the practical', especially with regards to the tensions surrounding perceptions of preferential treatment and competition around scarce resources between social groups in local areas.

\section{Part 2: Undoing the legacy of multiculturalism?}

As in their approach to increasing integration and building community cohesion and their model for developing 'a working sense of citizenship' described above, the CICC's approach with regards to tackling the 'tensions caused by diversity' also take on a particularly 'local' flavour. However, it will be suggested here that this approach is also highly reflexive in that the CICC's intention is to reduce the negative (and often unintended) impact of previous policies which are deemed to be exacerbating tensions between different groups in local areas. In his speech to mark the launch of the CICC Singh had the following to say:

My experience has shown that the way to tackle the tensions caused by diversity is at a local level. The job of local authorities is to balance diverse community interests to know when to say no, and to hammer out a way forward that manages competing demands and conflicting priorities. (Singh, 2006:2).

The CICC's approach to the tensions caused by diversity implied by Singh, above, results in a subtle twist to the Government's ambition since 2001 of attempting to find common ground in multi-ethnic, multi-faith and multicultural Britain through establishing shared values. Rather than attempting to overcome the tensions caused by diversity through the process of promoting 'unity in diversity' and forging common ground between diverse 
p. 53. 'A Past Built on Difference, a Future which is Shared' - a Critical Examination of the Recommendation made by the Commission on Integration and Community Cohesion

groups through establishing shared values, Singh suggests that what diverse communities at 'the sharp end of integration' have in common is 'the competition around access to resources' (2007:1). Therefore, rather encouraging debates on, for example, high level values and Britishness (see part 3 below) the CICC suggest that energy and resources should target the root of the problem, the source of the tensions and conflicts between specific communities in particular areas. According to the $\mathrm{CICC}$, it is the competition between groups for scarce resources and perceptions of preferential treatment which keep these tensions alive.

Now one recommendation made by the CICC in the interim statement has been granted special attention and has generated much discussion in the media. That is, the recommendation that the availability of Local Authority translation services should be reduced. According to the CICC these services promote dependence and separation through allegedly encouraging new migrants and settled migrant communities to remain non-English speakers. According to the MORI poll commissioned by the CICC, 60 per cent of people polled identified the inability of immigrants to speak English as a key issue (CICC 2007a:18). It was stated in the interim statement that lack of English language skills found in new arrivals and in 'settled communities' was a source of 'social distance' which is a barrier to integration and cohesion (2007a:18). It was also suggested that lack of English language skills hampers people's efforts to integrate economically and to access the labour market and it prevents them from developing a sense of belonging to bring them together with others (2007a:18). Thus the ability to speak English forms the bedrock of the dialogic, participatory and active citizenship that has been advocated by the Home Office since 2001. The Communities and Local Government Department (who commissioned the $\mathrm{CICC}$ ) can be described as continuing this emphasis. It will be argued here that perhaps too much attention has been given to the CICC's recommendation with regards to translation services. This is, after all merely an extension of the Government's 'linguistic nationalism' which focuses on the 'easiest signifier of sameness and difference' (Nortje and Marechera 2001:244) that is, the ability to speak English. Increasing proficiency in language skills is after all central to the 'managed integration' strategy associated with the new rituals of gaining British citizenship (McGhee, 2005) and therefore is not a recommendation unique to the CICC. The CICC's recommendation with regards to translation services is just one component in a wider set of recommendations associated with increasing integration and building community cohesion. It will be suggested here that the overwhelming focus found in the CICC's interim statement and in their final report is on reducing the tensions surrounding perceptions of preferential treatment, and this will be what I will focus on here. According to the MORI poll commissioned by the CICC, perceptions of preferential treatment are wide spread, that is,

Our MORI poll found that more than half of the people (56 per cent) feel that some groups in Britain get unfair priority when it comes to public services like housing, health services and schools. Fewer than one in seven (16 per cent) actively disagreed with the statement. This finding highlights that people are sensitive about perceived free-loading by other groups, and about others getting a better deal than them when it comes to certain public services. (CICC 2007b:33).

The CICC's analysis of the data form the MORI poll revealed that it was 'settled communities' 7 who were most worried about the fair allocation of public services, many of the respondents from settled communities believed that 'immigrants and minorities were getting special treatment' (CICC, 2007b:33). As will be revealed below, tensions over 
p. 54. 'A Past Built on Difference, a Future which is Shared' - a Critical Examination of the Recommendation made by the Commission on Integration and Community Cohesion

special or preferential treatment has become increasingly linked to multiculturalism. Now multiculturalism has been attacked on many fronts in recent years in Britain, perhaps most notably by Trevor Phillips when he was director of the CRE. For example, in his controversial speech: After 7/7: Sleep Walking into Segregation in September 2005, Phillips declared:

In recent years we've focused far too much on the 'multi' and not enough on common culture. We've emphasized what divides us over what unites us. We have allowed tolerance of diversity to harden into the effective isolation of communities, in which some people think special separate values ought to apply. (Phillips 2005: 8).

Ruth Kelly added her voice to the centre left critique of multiculturalism at the event launching the CICC. It was at this event that Kelly announced that 'we have moved from a period of uniform consensus on the value of multiculturalism, to one where we can encourage that debate by questioning whether it is encouraging separateness' (Kelly 2006a: 2). Multiculturalism for the CICC has become short-hand for preferential treatment. The particular aspect of the legacy of multiculturalism that the CICC are trying to distance themselves from is the divisive potential associated with implementing differential resource allocations to under privileged and marginalised groups (Anthias and Yuval-Davis 1992: 180), especially asylum seekers, refugees and new migrants (CICC 2007b: 33). The problematization of 'divisive' resource allocation that has the potential for generating accusations and perceptions of favouritism in local areas has been around for some time. However, what is interesting about the above is that this critique of multiculturalism, in the end, can be described less as a complete rejection of multiculturalism and more a tactic by the CICC in which they attempt to distance their new model for building community cohesion and increasing integration from the legacy of 'multiculturalism'. That is, the CICC's 'post-multiculturalism' strategy amounts to literally avoiding using the term, updating their language use, and adopting 'new' terms, that is,

our view is that we need to update our language to meet the current climate. We therefore intend to avoid using the term 'multiculturalism' in our report because of its 'catch all' and confusing quality. Our focus is on what practical policies we need to make our complex society work - where race, faith and culture are important, but not the only, elements of that complexity. (CICC 2007a: 13).

In the end, what is emerging here, especially in CICC's attempts to distance itself from the term multiculturalism, can be described as a 'practical' retreat from multiculturalism (Joppke 2004: 237) associated with the advent of a reflexive version of multiculturalism. The reflexive variety of multiculturalism described above should be distinguished from Ali Rattansi's 'framework of reflexive multiculturalism' (1999: 103). What is being described here is more akin with Beck's work on institutional reflexivity whereby societies attempt to rectify the side effects of existing practices, policies and laws (McGhee 2005). This is very much a top-down 'Government' derived reflexivity concerned with the maintenance of social order and conflict resolution. ${ }^{8}$ The reflexivity exhibited by the CICC is cognizant of (1) the simplistic reductionism associated with perceptions of identity, community and culture under multiculturalism and (2) the side-effects (for example, perceived favouritism and myths of preferential treatment) associated with the competition for scarce resources under multiculturalism. The CICC's reflexivity with regards to the former (associated with social science critiques of 'essentialist' multiculturalism) will be examined in part 3 . The 
p. 55. 'A Past Built on Difference, a Future which is Shared' - a Critical Examination of the Recommendation made by the Commission on Integration and Community Cohesion

CICC's recommendations in response to the latter, are that Local Authorities should be more proactive in the 'preventative action' they take 'to stop the spread of myths that arise from competition for resources' (2007b: 104) the major recommendation here is for Local Authorities to maintain a 'communication plan' based on a revised version of existing Local Authority Publicity Codes (2007b: 101). As well as recommending proactive action to counter the spread of myths of preferential treatment the CICC also recommend that the sources of local tensions around perceptions of preferential treatment could also be managed through embedding the principle of 'visible social justice' which they describe as 'a commitment to equal and fair treatment, combined with a transparency and fairness to all communities' (2007b: 97). The principle of visible social justice, according to the CICC, is not just a question of social justice "with its emphasis on fairness and an inclusive share of the benefits of economic prosperity' (2007b: 98). Visible social justice is primarily a reflexive strategy in that it is dedicated to 'making social justice visible to all groups in the community' (2007b: 98).

In the final report the CICC state that they have developed the principle of visible social justice 'in the context of a greater understanding of how settled communities may feel that positive action for minorities has unbalanced the way services are being provided' (2007b: 98). From this we can assume that what Hewitt refers to as the White Backlash (2005: 4) associated with the feelings that disadvantaged White communities perceive themselves to be the losers in the competition for scarce resources under multiculturalism might become a central concern in integration and community cohesion strategies in the future. ${ }^{9}$ In the next section the CICC's attempts to introduce a new model of identity that will correspond with their principle of visible social justice and their 'shared futures' discourse will be examined.

\section{Part 3: Commonality in multiplicity}

According to Singh the term multiculturalism 'belongs in 1967 not in 2007' (2007:1). The term he prefers is 'shared futures', which he describes as capturing 'what integration and cohesion really means to people' that is that 'the future can be shared even if the past is divided' (2007:1). Singh has borrowed the term 'shared futures' from the initiatives introduced to improve community relations in Northern Ireland (Darby and Knox, 2004). The term 'shared future' was used in Northern Ireland rather than an 'integrated' future to avoid connotations of assimilation of one group by the other group (Darby and Knox, 2004: 12). The utility of the shared futures discourse comes from the priority given to creating a sense of common purpose rather than prioritizing the creation of a common identity (Holloway, 2004: 17). The Shared futures discourse has much in common with Gordon Brown's new 'Britishness' discourse in which he attempts to de-emphasise ethnic nationalism ${ }^{10}$ in favour of a nationalism, or more accurately a patriotism, ${ }^{11}$ of "common purpose'. For example, in his 'The Future of Britishness' speech delivered at the Fabian Britishness Conference in January 2006 Brown was keen to make the distinction between ethnic nationalism and his vision of patriotic civic nationalism ${ }^{12}$ which he described as a 'sense of common patriotic purpose' (Brown, 2006: 3), that is:

This British patriotism is, in my view, founded not on ethnicity nor race, not just on institutions we share and respect, but on enduring ideals which shape our view of ourselves and our communities - values which in turn influence the way our institutions evolve. (Brown, 2006:4). 
p. 56. 'A Past Built on Difference, a Future which is Shared' - a Critical Examination of the Recommendation made by the Commission on Integration and Community Cohesion

Thus Brown envisages the nation as 'a community of equal, rights-bearing citizens, united in patriotic attachment to a shared set of political practices and values' (Ignatieff 1993:6). This is where the similarity between Brown's new British patriotism discourse and the CICC's promotion of the shared futures discourse ends. The CICC consider 'British values' to be 'high values' which are often exclusive and inappropriate for building community cohesion and increasing integration in all circumstances. The CICC viewed the pursuit of 'British values' with some ambivalence. It was stated in the CICC's final report that 'we have to be reminded that while "high level values" can be held in common, there can be still be substantial disagreement about how to apply them to particular circumstances' (CICC, 2007b:65). Rather than going down the road of over-emphasisizing 'shared British values' the CICC's shared futures discourse emphasized a rearticulation of both local and national identities away from the pitfalls of past-orientated 'Britishness' and what they see as the reified and stereotypical identities associated with multiculturalism (Phillips, 2007: 14). In the final report, the CICC state that 'from now on both local and national identities need to be about shared futures' (2007b:47). To achieve this aim the CICC's shared futures discourse is being promoted alongside a poststructuralist perspective on 'real world' multiple, identities, that is:

People are moving away from single identities to multiple identities not just based on race or ethnicity, but differences in values, differences in life-style, consumption, social class, differences across generations, gender etc. People now have multiple identities and adjust these to the situation they are in - and this seems particularly true for the children or grandchildren of migrants. (2007b:34).

Multiple, complex identities seems to be the means whereby greater commonality between groups can be encouraged, that is:

It seems at times that we have lost sight of the complexity of individual identity, its fluid nature, and the ability in the real world to identify with different things at the same time - to be a woman or a man, within a particular ethnic group, or a particular social class - and the ability to share hopes and fears with others or not of your group. (CICC, 2007b:46).

The CICC's shared futures discourse is a discourse of 'mutual interdependence' (2007b:46) which involves everyone 'moving forward together' as a result of different groups relinquishing their attachments to the past through moving away 'from narrow identities towards a vision of the future shared by different groups' (2007b:46). In many ways the CICC's perspective fuses the social science critiques of reified 'cultures' associated with mosaic multiculturalism (Benhabib, 2002:8) with the 'new ethnicities' theory of identities to promote their 'shared futures' agenda. Modood describes the criticism of reified cultures associated with multiculturalism from social scientists as being anti-essentialist in that the central theoretical criticism against multiculturalism is that '... "cultures" or "groups" do not exist in the ways presupposed by multiculturalism' (2007: 89). This is a perspective which views cultures as 'discrete, frozen in time, impervious to external influences, homogeneous and without internal dissent' (Modood, 2007: 89). For Gilroy, these are both essentialist and reductive conceptions which feed into the belief in the insurmountable nature of ethnic categories (1992: 50) which, according to Yuval-Davis, are associated with both multiculturalist and anti-racist strategies holding the autonomy of 
p. 57. 'A Past Built on Difference, a Future which is Shared' - a Critical Examination of the Recommendation made by the Commission on Integration and Community Cohesion

minority communities sacred (1992:281). This critique of cultural essentialism and what Parekh refers to as 'cultural conservatism' (2000:79) is combined in the CICC with a theory of identities derived from new ethnicities theory associated with multiple, complex and fluid identities (Back, 1996; Cohen, 1999; Mac an Ghaill, 1999).

The CICC's combination of a seemingly anti-essentialist post-multiculturalist discourse with a poststructuralist informed perspective on identities and is not just an academic exercise. Multiple identities and multiple identifications are particularly significant for the CICC's shared futures discourse for 'practical' reasons. For example, (1) multiple identifications are being presented for the purposes of facilitating the discovery of commonality between diverse individuals. That is, the $\mathrm{CICC}$ suggest that 'fluid identities can also act to bring people together as they discover, for example, experiences common to women or sporting interests, which cut across other potential single group conflicts' (CICC, 2007b 34-35). Thus, multiple identifications in people will facilitate the process of people identifying with each other and working towards a shared future together. At the same time, (2) the CICC suggest that research in Northern Ireland 'has found that people with more complex and multiple sources of identity are more positive about other groups, more integrated and less prejudiced' (2007b:35). Thus multiple identifications in people could perform the positive social role of reducing conflict between groups. Furthermore, (3) Multiple identifications could also lessen tensions surrounding the competition for scarce resources between groups when difference is no longer used as a 'bargaining chip' to gain small advantages over other groups (CICC, 2007b:98). The CICC's perspective on multiple identities is used to disrupt what they see as the root cause of community cohesion and integration problems: ethnocentricity. Feuchtwang describes ethnocentricity as the universal psychological trait of sorting people into groups according to their cultural differences (1990:5). This is associated with the process of categorizing individuals into populations according to a plurality of origins, conceived as 'communities of identity' (Feuchtwang, 1990:5). Benhabib, takes Feuchtwang observations further by describing this practice as a process of othering. According to Benhabib, 'a self is only a self because it distinguishes itself from real, or more often imagined "other(s)". For Benhabib, struggles for recognition among individuals and groups are really efforts to negate the status of "otherness", insofar as otherness is taken to entail disrespect, domination, and inequality' (2002:8). Ethnocentricity and othering, in the CICC is to be replaced through promoting a perspective on multiple identities that is intended to initiate a process cosmopolitanization (Beck, 2002). Cosmopolitanization is described by Beck as an 'alternative imagination, an imagination of alternative ways of life and rationalities, which includes the otherness of the other' (Beck 2002: 18). The problem here is that the CICC have overemphasized cultural factors (identity, culture, communication) over their material and structural context (McGhee, 2003). The CICC's promotion of multiple identities as the means to overcoming 'communal' tensions and competition is evidence of what Cohen describes as the hegemony of a one-sided new ethnicities theory of identity which instituted a new moral binarism between 'good, new' ethnicities which celebrated healthy, happy hybridity, and the 'bad, old' ethnicity mired in pathological purity (1999:7). Cohen reminds us that the forerunner of the new ethnicities perspective was Stuart Hall. Hall urged us to recognize that we are composed of multiple social identities, not singular identities. However, Hall also urged us that our complex identities which were complexly constructed through different categories and different antagonisms, may have the effect of locating us socially in multiple positions of marginality and subordination (1991:57). According to Cohen, it is this aspect of the new ethnicities theory that has been lost. In the rush to celebrate multiple, fluid, diasporic, transnational, transracial and hybrid identities social scientists 
p. 58. 'A Past Built on Difference, a Future which is Shared' - a Critical Examination of the Recommendation made by the Commission on Integration and Community Cohesion

and politicians alike have forgotten Hall's concerns with regards to the impact of structural and cultural racism (Cohen 1999:7). Multiple and complex identities are lived in particular socio-political contexts. Just because we celebrate multiple identities does not necessarily prevent the persistence of individuals also occupying multiple positions of marginalization and subordination. Thus, class position, gender position and economic and political relations (Anthias, 1998:525) those 'structured forms of inequalities' (Bottero, 2005:102) are absent from much of the recent debates on 'new ethnicities' (Anthias, 1998:525). The CICC's one-sided celebration of multiplicity perpetuates this marginalization of the multiple forms of structural inequalities.

There are further 'practical' reasons for the CICC's promotion of multiple identities. That is, the primary reason the CICC are so keen on introducing the benefits of multiple identifications was in order to promote and legitimize a 'regime change' in both Government and non-Government funding for 'single groups'. This will be explored in the next part.

\section{Part 4: Single group funding}

The CICC's recommendations with regards to funding were set out in Annex D of the final report. Annex D was entitled 'The Question of Single Group funding'. Single group funding is defined in the Annex as funding 'awarded on the basis of a particular identity, such as ethnic, religious or cultural' (2007b:160). The CICC consider 'single group funding' to be a hangover from

Old identity politics - with groups encouraged to shout loudly about their own individual needs, rather than being encouraged to come together to access funding for shared activities enabling bridging and interaction. (CICC, 2007b:162)

The CICC appreciated the reasons why single group funding emerged in the first place, for example, to meet the unmet needs of particular groups, to counter the direct or indirect discrimination experienced by particular groups from mainstream service providers and to enable the delivery of services in culturally appropriate ways (CICC, 2007b:161). However, according to the CICC, their consultation had demonstrated that single group funding had become associated with considerable disadvantages some of these have already been examined in part 2 above, for example, tensions around perceptions of preferential treatment and the divisive competition between groups for resources. However, the CICC also presented other disadvantages associated with single group funding which demonstrated the Commissions' appreciation of social capital theory, especially the hazards associated with encouraging bonding rather than bridging social capital (Putnam, 2000; Gilchrist, 2004) most recently associated with the Cantle Report of 2001 (McGhee, 2003; 2005). Putnam et al. (2003) suggest that social capital refers to social networks, norms of reciprocity, mutual assistance and trustworthiness. They explain the distinction between 'bonding' and 'bridging' social capital thus: 'some networks link people who are similar in crucial respects and tend to be inward-looking - bonding social capital. Others encompass different types of people and tend to be outward-looking - bridging social capital' (2003: 2). The problem is that bridging social capital is harder to create than bonding social capital; and bridging social capital, according to Putnam et al. '...is the kind of social capital that is most essential for healthy public life in an increasingly diverse society...' (2003:3). I have suggested elsewhere that the recommendations with regards to 
p. 59. 'A Past Built on Difference, a Future which is Shared' - a Critical Examination of the Recommendation made by the Commission on Integration and Community Cohesion

transforming bonding to bridging social capital found in the Cantle Report can be described as encouraging local people to alter their ways of thinking about, doing and being communities which can be described as a problematization of habitus (McGhee, 2005:54)..$^{13}$ A very similar process is in operation with regards to the CICC's recommendations on single group funding. For example, the $\mathrm{CICC}$ suggested that single group funding has the potential 'to increase insularity and a sense of separation where the project funded is only or mainly for the group in question' (2007b: 161) this could lead to 'a sense in which a "comfort zone" could be developed if communities were not encouraged to be outward-facing, and therefore only mixed with others in their group' (CICC, 2007b:161). The CICC's solution to the alleged disadvantages of single group funding is that public sector funding for bodies representing particular communities should come with a requirement to demonstrate that their actions support integration and cohesion (CICC, 2007b:161). What becomes clear in Annex D of the final report is that the CICC's opposition to single group funding is linked to their reflexive project of reducing intercommunity tensions around perceptions of preferential treatment and the divisive competition for resources through promoting the idea of visible social justice. That is, "we are clear that whatever the type of area, all funding should be transparent and open to scrutiny - and that funding decisions should be communicated clearly and to all communities. This is particularly important given the evidence we have seen of the damaging myths perpetuated around preferential treatment' (CICC, 2007b: 162). In many ways the CICC's anti-single group funding policy, advances the recommendations on funding found in the Cantle report. In the Cantle Report it was suggested that funding bodies should 'presume against separate funding for distinct communities, and require collaborative working, save for the circumstances where the need for funding is genuinely only evident in one section of the community and can only be provided separately' (Home Office, 2001: Para. 6.45). The CICC's recommendations on single group funding attempt to formalise 'the presumption' found in Cantle in that it is an explicit funding policy recommendation designed to 'manipulate and re-channel existing identity practices in what are seen as more positive directions' (Wetherell, 2007:13) with the intention of reeducating diverse communities 'unarticulated forms of habitus' (2007:13). This rechannelling and re-education process is to be achieved through breaking what have been viewed since the publication of the Cantle Report as bad (insular, bonded, defensive) 'social capital habits' in order to promote outward-looking, collaborative and bridging activities and initiatives in local areas.

\section{Conclusion}

The legacy of the CICC will not necessarily be the 'progressive' yet naive vision of Britain being encouraged to move to its shared future. Rather, the legacy of this Commission could well be the promotion in Government circles of a new public funding regime whereby 'single group funding' will be 'the exception rather than the rule for both Government and external funders' (CICC, 2007b:160). This 'new climate of thinking' (Harrison, 2005:88) has been around since the publication of the Cantle Report. In many ways the CICC has simply coopted existing discourses on the funding of 'community projects' as being the means of promoting what is unproblematically assumed to be 'the right kind' of social capital.

The CICC's attempts to achieve discursive coherence between political and social science discourse on multiculturalism, identity and citizenship have merely reproduced many of the problems it set out to avoid. In the end, despite their promotion of a multi- 
p. 60. 'A Past Built on Difference, a Future which is Shared' - a Critical Examination of the Recommendation made by the Commission on Integration and Community Cohesion

faceted discourse of complexity and their explicit rejection of strategies that focus on 'single issues' such as 'residential segregation' the CICC can be accused of not practicing what they preach. In their interim statement and in their final report all roads lead to their over-riding concern with one issue: perceptions of preferential treatment.

In the end, the CICC's has ended up perpetuating what Darra Singh views himself and his fellow Commissioner's as fighting against, that is, simplicity. One could say that despite their rejection of approaches that focus on 'single issues' such as residential segregation the CICC has itself been 'sleepwalking into simplicity'. The CICC's reflexivity with regards to what they view as the primary negative legacy of multiculturalism could leave those who read this statement and report with the view that the only real issue obstructing Britain's move to being a more cohesive and integrated society is persistent perceptions that certain groups are enjoying preferential treatment and some groups are not. The problem is the CICC can be accused of only partially rejecting the flawed approaches adopted by Cantle and even David Blunkett in their responses to the disturbances in Oldham, Burnley and Bradford in 2001. One could say that Cantle's contact hypothesis, co-option of social capital theory and recommendations on 'community group' funding and even the suggestions for developing a revitalized sense of British citizenship are alive, well and fully present (in seemingly unmodified form, despite the CICC's 'distancing' strategies) in the CICC's interim statement and final report.

\section{Notes}

1 For example, Cantle's Community Cohesion Review (2001), Denham's Building Cohesive Communities (2002), various Local Government Association guidelines and Action on Community Cohesion (2002, 2004, 2006), the Community Cohesion Panel's End of Parallel Lives? report (2004) as well as various Home Office derived strategies and consultation strategies: Strength in Diversity (2004), Improving Opportunities and Strengthening Society (2005), as well as Crick's The New and the Old: Life in the UK Advisory Group Report (2003) and White Papers devoted to managing migration and integration, for example: Secure Borders - Safe Haven (2002) and Controlling Our Borders; Making Migration Work for Britain (2005), to name just a few.

2 The reports will be referenced as CICC (2007a) and CICC (2007b) respectively.

3 This report was commissioned by the Home Office in response to the social disorder in Oldham, Burnley and Bradford during the summer of 2001.

4 This definition is based upon a modified version of the definition of 'a cohesive community' found in Local Government Association Guidelines (2002) which has been consistently used in the 2004 and 2006 Guidelines. According to the Local Government Association a cohesive community is one where:

- There is a common vision and a sense of belonging for all communities.

- The diversity of people's different backgrounds and circumstances is appreciated and positively valued.

- $\quad$ Those from different backgrounds have similar life opportunities.

- Strong and positive relationships are being developed between people from different backgrounds in the workplace, in schools and within neighborhoods.

(Local Government Association 2002: 6).

5 The terms of reference for the CICC were listed as:

- Examining the issues that raise tensions between different groups in different areas, and that lead to segregation and conflict; 
p. 61. 'A Past Built on Difference, a Future which is Shared' - a Critical Examination of the Recommendation made by the Commission on Integration and Community Cohesion

- Suggesting how local community and political leadership can push further against perceived barriers to cohesion and integration;

- Looking at how local communities themselves can be empowered to tackle extremist ideologies;

- Developing approaches that build local area's own capacity to prevent problems, and ensure they have the structures in place to recover from periods of tension.

(eGov Monitor 2006: 1)

6 Darra Singh became Chief Executive of Ealing Council in April 2005 after four years as Chief Executive at Luton Council.

7 By settled communities, the CICC is referring to White communities and settled migrant communities.

8 Rattansi's framework for a reflexive multiculturalism, should be distinguished from the above. Rattansi's reflexive multiculturalism bears 'many similarities with critical multiculturalism', according to Rattansi, as well as being influenced by Giddens's notion of reflexivity which emphasises 'the reflexivity of agents and subjects' and the significance of 'expert systems' of knowledge (Rattansi 1999: 104).

9 This is not just supposition, the social exclusion and felt injustice of disadvantaged White communities was particularly emphasised by Singh in his foreword to the interim report (see also McGhee forthcoming), that is:

Our consultation has highlighted a question about re-balancing our perspective. We may need to challenge what can be interpreted by some as an obsession with a narrow focus on minorities and think more 'broadband'. $39 \%$ of the population live in the 86 most deprived areas - that is 19.1 Million people. Although $65 \%$ of people from ethnic minority groups live in these areas, the majority - over 16 million - are White. It is time that we created a clear and explicit strategy to connect with longer term established communities as well as dealing with the most vulnerable of the new and emerging groups?

(Singh, in CICC 2007a: 3).

10 According to Michael Ignatieff, ethnic nationalists define the nation in terms of ethnic origins and birth (1996: 219). Under ethnic nationalism, 'allegiance is directed primarily at the nation, at the traditions, values, and cultures incarnated in a people's history' (Ignatieff 1996; 219).

11 In this speech Brown attempts to distinguish the 'old' discourse of 'patriotism as nationalism' associated with right wing jingoism, to promote, in its place, a new variety of patriotism that stresses 'the importance of political loyalty to a democratic polity and citizens' through a commitment to the common principles underpinning liberal democratic cultures (Kostakopoulou 2006: 75).

12 For Michael Ignatieff, civic nationalist 'define the nation not in terms of ethnicity but in terms of willingness to adhere to its civic values' (Ignatieff 1996: 219).

${ }^{13}$ According to Bourdieu, habitus can be defined as a system of dispositions that designate ways of being, habitual states; in particular predispositions, tendencies, propensities and inclinations (1977: 214).

* Correspondence Address: Derek McGhee, Division of Sociology and Social Policy, University of Southampton. Email: d.p.mcghee@soton.ac.uk. 
p. 62. 'A Past Built on Difference, a Future which is Shared' - a Critical Examination of the Recommendation made by the Commission on Integration and Community Cohesion

\section{Bibliography}

Amin, A. (2002) Ethnicity and the Multicultural City: Living with Diversity. Draft report for the ESRC Cities Programme and the Department of Transport. Local Government and the regions (DTLR). http: //www.livjim.ac.uk/cities/papers/ash_amin.pdf.

Anthias, F. (1998) Rethinking Social Divisions: Some Notes on a Theoretical Framework. The Sociological Review, 46, 3, 505-535.

Beck, U. (2002) The Cosmopolitan Society and its Enemies. Theory, Culture \& Society, 19, 1-2, 17-44.

Back, L. (1996) New Ethnicities and Urban Culture: Racisms and Multiculture in Young Lives. London, Routledge.

Benhabib, S. (2002) The Claims of Culture: Equality and Diversity in the Global Era. Princeton \& Oxford, Princeton University Press.

Blunkett, D. (2004) New Challenges for Race Equality and Community Cohesion in the $21^{\text {st }}$ Century, the Institute of Public Policy Research, $7^{\text {th }}$ July 2004. http://www.homeoffice.gov.uk/comrace.

Blunkett, D. (2002) Integration with Diversity: Globalization and the Renewal of Democracy and Civil Society. Foreign Policy Centre. http://www.fpc.org.uk/articles/182.

Brown, G. (2006) The Future of Britishness, Speech at Fabian Britishness Conference, 14 ${ }^{\text {th }}$ January, http://www.fabian-society.org.uk/press office/news latest all.asp?pressid=520

Bottero, W. (2005) Stratification: Social Division and Inequality. London \& New York, Routledge.

Bourdieu, P. (1977) Outline of a Theory of Practice. Cambridge, Cambridge University Press.

Cohen, P. (1999) Through a Glass Darkly: Intellectuals on Race, in P. Cohen (ed) New Ethnicities, Old Racisms. London, Zed Books: 1-17.

Commission on Integration and Community Cohesion (2007a) Our Interim Statement, www.integrationandcohesion.org.

Commission on Integration and Community Cohesion (2007b) Our Shared Future, www.integrationandcohesion.org.

Communities and Local Government (2007) Blears - 50 Million Investment in Community Cohesion, 6 $6^{\text {th }}$ October, http://www.communities.gov.uk/news/corporate/500395.

Community Cohesion Panel (2004) The End of Parallel Lives? http://www.communities.gov.uk/index.asp?id=1505128

Darby, J. and Knox, C. (2004) 'A Shared Future': a Consultation Paper on Improving Relations in Northern Ireland, final report, $21^{\text {st }}$ January, http://www.asharedfutureni.gov.uk/colin knox john darby.pdf.

Denham, J. (2002) Building Cohesive Communities: a report of the ministerial group on public order, HMSO. http://www.communities.gov.uk/publications/ communities/publicordercohesion

eGov Monitor (2006) New Commission on Integration and Cohesion, http://www.egovmonitor.com/node/7342/print, 1-3.

Feuchtwang, S. (1990) Racism: Territoriality and Ethnocentricity, in A. X. Cambridge \& S. Feuchtwang (eds) Antiracist Strategies, Gower Publishing Company Ltd: Aldershot, 326.

Gilroy, P. (1992) The End of Antiracism, in J, Donald and A. Rattansi (Eds) 'Race', Culture and Difference, Sage Publications Ltd: London, 49-61. 
p. 63. 'A Past Built on Difference, a Future which is Shared' - a Critical Examination of the Recommendation made by the Commission on Integration and Community Cohesion

Harrison, M. (2005) From Community Cohesion to an Inclusion and Co-Operation Agenda, in M. Harrison, D. Phillips, K. Kusminder, L. Hunt and J. Perry (Eds) Housing, 'Race' and Community Cohesion, Chartered Institute of Housing: Coventry, 82-102.

Hewitt, R. (2005) White Backlash: and the Politics of Multiculturalism. Cambridge, Cambridge University Press.

Holloway, D. (2004) Identity and the Northern Ireland Conflict: an Overview, Community Dialogue, March, http://www.communitydialogue.org/identityAndTheNorthernIreland Conflict.html

Home Office (2005b) Controlling Our Borders: Making Migration Work for Britain, http://www.archive2.official-documents.co.uk/document/cm64/6472/6472.pdf

Home Office (2005a) Improving Opportunities, Strengthening Society: The Government's Strategy to Increase Race Equality and Community Cohesion. London, Home Office.

Home Office (2004b) Strength in Diversity: towards a community cohesion and race equality strategy. Home Office Communication Directorate. http://www.homeoffice.gov.uk/comrace.

Home Office (2002) Secure Borders, Safe Haven: integration with diversity in Modern Britain. London, Home Office, CM 5387.

Home Office (2001) Community Cohesion: a Report of the Independent Review Team (Chaired by Ted Cantle). London. Home Office. http://www.home office.gov.uk/comrace.

Ignatieff, M. (1996) Nationalism and Toleration, in R. Caplan and J. Feffer (Eds) Europe's New Nationalism: States and Minorities in Conflict. Oxford, Oxford University Press, 213-232.

Joppke, C. (2004) The Retreat of Multiculturalism in the Liberal State: Theory and Policy. British Journal of Sociology, 55, 2, 241-250.

Kalra, V.S. (2002) Riots, race and reports: Denham, Cantle, Oldham and Burnley inquiries. Sage Race Relations Abstracts, 27, 4, 20-30.

Kelly, R. (2006a) Britain: Our values, Our responsibilities, Speech to Muslim Organizations on Working Together to Tackle Extremism Together, 11 $1^{\text {th }}$ October, http://www.communities.gov.uk/index.asp?id=1503690

Kelly, R. (2006b) Speech by Ruth Kelly at the Launch of the Commission on Integration and Community Cohesion, 24th August, http://www.communities.gov.uk/index.asp? $i d=1502280$.

Kostakopoulou, D. (2006) Thick, Thin and Thinner patriotism: Is This All There Is? Oxford Journal of Legal Studies, 26, 1, 73-106.

Kundnani, A. (2001a) From Oldham to Bradford: the violence of the violated. Race \& Class, 43, 2, 105-31.

Kundnani, A. (2001b) In a Foreign Land: the new popular racism. Race \& Class, 43, 2, 4160.

Life in the United Kingdom Advisory Group (2003) The New and the Old: Report of the Life in the United Kingdom Advisory Group, Home Office, http://www.ind.homeoffice.gov.uk/6353/aboutus/thenewandtheold.pdf.

Local Government Association (2006) Leading Cohesive Communities: a guide for local authorities and chief executives, Local Government Association.

Local Authority Association (2004) Community Cohesion - an action guide. Local Government association.

Local Government Association (2002) Guidance on Community Cohesion. Local Government association. 
p. 64. 'A Past Built on Difference, a Future which is Shared' - a Critical Examination of the Recommendation made by the Commission on Integration and Community Cohesion

Mac an Ghail, M. (1999) Contemporary Racisms and Ethnicities. Buckingham, Open University Press.

McGhee, D. (forthcoming) The End of Multiculturalism? Terrorism, Integration \& Human Rights. Open University Press \& McGraw-Hill Education.

McGhee, D. (2005) Intolerant Britain?: Hate, citizenship \& difference. Berkshire, Open University Press \& McGraw-Hill Education.

McGhee, D. (2003) Moving to 'our' common ground - a critical examination of community cohesion discourse in twenty-first century Britain. Sociological Review, 51, 3, 383411.

Modood, T. (2007) Multiculturalism (Themes for the 21st Century). Cambridge, Polity Press.

Nortje, A. \& Marechera, D. (2001) Lines of Flight: Bessie Head, in A. O'Brien (ed) Against Normalization: Writing Radical Democracy in South Africa. Durham \& London, Duke University Press, 215-256.

Parekh, B. (2000) Rethinking Multiculturalism: Cultural Diversity and Cultural Theory. Basingstoke, Palgrave.

Phillips, A. (2007) Multiculturalism without Culture. Princeton \& Oxford, Princeton University Press.

Phillips, T. (2005) After 7/7: Sleepwalking into Segregation, 22 ${ }^{\text {nd }}$ September, Manchester Town Hall, http://www.cre.gov.uk/Default.aspx.LocID-Ohgnew07r.RefLocIDOhg00900c001001.Lang-EN.htm.

Putnam, R. D. (2000) Bowling Alone: the collapse and revival of American Community. New York, Simon \& Schuster.

Putnam, R., Feldstein, L. and Cohen, D. (2003) Better Together: Restoring the American Community. Australia, Simon \& Schuster.

Rattansi, A. (1999) Racism, 'Postmodernism' and Reflexive Multiculturalism, in S. May (Ed) Critical Multiculturalism: Rethinking Multiculturalism and Anti-Racist Education, Falmer Press: Taylor and Francis Group, 77-112.

Singh, D. (2006) Speech by Darra Singh at the Launch of the Commission on Integration and Community Cohesion, http://www.communities.gov.uk/index.asp?id=1502287

Singh, D. (2007) Not Speaking English is the single biggest barrier to successful integration, Commission on Integration and Community Cohesion, speech to launch Interim Report, http://.integrationandcohesion.org.uk/news/Not speaking english is the sigle_biggestbarrier_to successful_integration.aspx

Wetherell, M. (2007) Introduction, Community Cohesion and Identity Dynamics: Dilemmas and Challenges, in M. Wetherell, M. Laflèche and R. Berkeley (Eds) Identity, Ethnic Diversity and Community Cohesion, London: Sage Publications, 1-14.

Yuval-Davis, N. (1992) Fundamentalism, Multiculturalism and Women in Britain, in J, Donald and A. Rattansi (Eds) 'Race', Culture and Difference, Sage Publications Ltd: London, 278-292. 